\title{
BMJ Open Qualitative exploration of lesbian parents' experiences of accessing healthcare for their adopted children in England
}

\author{
Lucille Kelsall-Knight
}

To cite: Kelsall-Knight L. Qualitative exploration of lesbian parents' experiences of accessing healthcare for their adopted children in England. BMJ Open 2021;11:e053710. doi:10.1136/ bmjopen-2021-053710

- Prepublication history for this paper is available online. To view these files, please visit the journal online (http://dx.doi. org/10.1136/bmjopen-2021053710).

Received 24 May 2021 Accepted 22 September 2021

Check for updates

(C) Author(s) (or their employer(s)) 2021. Re-use permitted under CC BY-NC. No commercial re-use. See rights and permissions. Published by BMJ.

School of Nursing, College of Medical and Dental Sciences, University of Birmingham, Birmingham, UK

Correspondence to Dr Lucille Kelsall-Knight; L.M.Kelsall-Knight@bham.ac.uk

\section{ABSTRACT}

Objective To explore the experiences of lesbian parents accessing healthcare for their adopted children in England. Design A qualitative inductive design, using narrative inquiry with a critical incident recall interview approach. Interviews were analysed using merged tools of critical event analysis and broadening, burrowing, storying and restorying.

Setting Participants were recruited from a British lesbian, gay, bisexual and transgender fostering and adoption charity.

Participants Six lesbian adoptive parents with experience of accessing healthcare for their adopted children in England.

Results Following data analysis, five themes were identified: navigating heteronormativity, navigating healthcare settings and professionals and having an 'adopted' status, intersectional identity of lesbian-parented adoptive families accessing healthcare, reflective imagery of lesbian parents and adoptive families and professional expectations. Self-imposed strategies instigated by the parents to strengthen and protect their familial identities were also discovered.

Conclusions The needs and challenges of lesbian adoptive families may be different to those of heterosexual and biological families when accessing healthcare. There was an undercurrent of discriminatory practice, shown by various healthcare professionals, and a lack of understanding of the adoption process, knowledge surrounding the child's history and legal stance with regards to parental responsibility. Further training is needed for healthcare professionals.

\section{INTRODUCTION}

Family demographics have changed in recent history and it is now more common in the UK for parents to identify as lesbian, gay, bisexual and transgender (LGBT). ${ }^{12}$ The Adoption and Children Act, ${ }^{3}$ which became legislation on 30 December 2005 in England and Wales, stated that an application to adopt a child could be made by either a single person or a couple and there was no necessity to be married or heterosexual. Prior to the passing of this Act, ${ }^{3}$ lesbians were recognised as
Strengths and limitations of this study

- Three-stage approach to the interviews with critical incident recall allowed the participants to speak freely about the topic.

- Creation of a composite character couple not only provided anonymity for the participants but also 'brought to life' their stories.

- The narratives in this study provided a rich source of data about the lesbian parents' perspective of accessing healthcare for their adopted children, therefore, information is only obtained from one section of the lesbian, gay, bisexual and transgender community.

- There were a small number of participants in this qualitative study and the National Health Service provides healthcare across the UK, but no participants were recruited from Wales, Scotland or Northern Ireland.

parents under English law, but they had most commonly become parents as a result of a previous heterosexual union, artificial insemination or surrogacy. ${ }^{4-7}$ The total number of same-gender parents in the UK is unknown; however, in 2020, one in six children in England were adopted by same-gender couples. ${ }^{8}$

There are numerous studies detailing LGBT people's experiences of healthcare in terms of their access to and use of services. ${ }^{9-11}$ However, there is a lack of research concerning LGBT parents' experiences of accessing healthcare services for their children. ${ }^{12-21}$ It is not clear why there is a paucity of research on this topic, but it may be due to these parents' discomfort in heterosexist healthcare environments, ${ }^{22-24}$ and a reluctance to disclose sexual orientation,,$^{25}$ potentially because of previous discriminatory experiences in healthcare environments. ${ }^{26-28}$

Due to their early life experiences, there is an increased occurrence of adopted children accessing mental health services and 
attending dental and medical appointments than biological children. ${ }^{29-31}$ Therefore, LGBT adoptive parents' experiences of accessing healthcare services on behalf of their children is particularly important to ensure that it is inclusive and is being conducted in accordance with the Equality Act, ${ }^{32}$ and that professional standards are being adhered.

In the majority of cases, health needs in England are met by the National Health Service (NHS). Healthcare professionals are governed by professional and statutory regulatory bodies and have to adhere to codes of conduct $^{33-35}$ that include acting without discrimination. Notwithstanding the law, policy and government recommendations, ${ }^{32} 36{ }^{37}$ homophobia remains present in many UK institutions, including the NHS, with patients and their families reporting discriminatory comments about sexual orientation. ${ }^{38}$

\section{Aims}

To explore

1. How lesbian parents describe their experiences of healthcare consultations for their adopted children in England.

2. How the family unit acknowledged within the healthcare journey.

3. The perceptions of the lesbian parents when accessing healthcare for their adopted children.

\section{METHODS}

\section{Design}

This study adopted a qualitative inductive design, using a narrative inquiry approach. Narrative inquiry considers the relationship between the experience that the individual has encountered and the cultural context of it. ${ }^{39}$ Research embedded in narrative is not an exact imitation of an event or experience, but it can be used to aid in the creation of reality and to make sense of events for the individual person and to contextualise them in relation to the social, political and cultural environment. ${ }^{39}$ Critical incident recall interviews were conducted via Skype by LKK with the lesbian parents who had experienced accessing primary, secondary and/or tertiary healthcare with their adopted child/ren, and they were audio-recorded and then transcribed verbatim. Data were analysed using a merged tool of critical event analysis ${ }^{40}$ and broadening, burrowing, storying and restorying. ${ }^{39}$ The study adhered to COnsolidate criteria for REporting Qualitative research (COREQ) guidance.

\section{Patient and public involvement}

No patients were involved. Participants were involved via member checking and agreement with characteristics of composite character couple. The results were disseminated to the study participants in the final interview.

\section{Participants}

The participants were purposively recruited through an advertisement on an online forum hosted by New Family
Social, a British charity, led by LGBT adoptive parents and foster carers. Parents self-identifying as cis-gendered lesbians and having experience of accessing healthcare for their adopted child/ren were invited to take part in the study. The six participants were aged 30-39 years, were in same-gender relationships and were from four families. Their children ranged in age from 2 to 7 years old. It was a prerequisite that the child/ren were adopted from the UK from either a local authority or voluntary adoption agency. Four of the participants had university degrees and two had completed further education study. One participant was not born in the UK. One participant was dual heritage (white Caucasian and black Caribbean) and five were white Caucasian. All participants gave both written and verbal informed consent.

There was a total of six stories, two stories were told collaboratively by two members of a couple (the researcher provided autoethnographical data during the pilot study) and two stories had one perspective.

\section{Data collection}

The interviews took place via Skype from October 2018 to March 2019. The participants were asked to discuss a critical incident that had occurred when accessing and/ or receiving healthcare for their adopted child/ren. Critical incidents are snapshots of something, positive or negative, that happens to a patient or their family. ${ }^{41} \mathrm{~A}$ three-stage interview process was conducted. In the first interview, which lasted 20 minutes, the researcher introduced herself to the participants, including her personal and professional positioning and gathered demographic data, the participants were also asked to think about any critical incidents in time for the next stage of the interview process. The researcher disclosed that she was a registered children's nurse and also a lesbian adopter who had accessed healthcare for her children but did not disclose any critical incidents from her own experience. The critical incident interview was the second interview, which lasted approximately 60 minutes in length, and the only structure was asking the participant/s to recall a critical incident and to ascertain if they had seen any positive imagery around adoptive families within the health setting. Data saturation was determined when there was adequate data to develop an understanding of the study phenomenon, and further coding was no longer necessary. The third interview (20 minutes) was held once the interviews had been analysed. This provided an opportunity to discuss the initial findings and to 'sense-check' that the participants' story has been interpreted in the way that they had meant it to be understood. All the participants agreed with the themes that had been determined through their story.

\section{Analysis}

Interviews were analysed by (LKK) using a merging of the data analysis tools of Clandinin and Connelly ${ }^{39}$ and Webster and Mertova. ${ }^{40}$ Data were manually coded and analysed individually for thematic content and for stories 
that followed dominant discourses, as well as for stories that did not, but were 'like or other events' to the critical incident. ${ }^{40}$ Once the events were grouped, the analytical tools of broadening, burrowing, storying and 'restorying ${ }^{39}$ were adopted. A composite character couple was designed as a vehicle to tell the 'restory' of the participants. The names of the composite characters, Sarah and Harriet as the parents of Courtney and Michael, are fictitious and their individual characteristics were determined by the reflection of the demographical data of the study participants.

Five themes were identified: navigating heteronormativity, navigating healthcare settings and professionals and having an 'adopted' status, intersectional identity of lesbian-parented adoptive families accessing healthcare, reflective imagery of lesbian parents and adoptive families and professional expectations.

\section{FINDINGS}

Findings are viewed through the lens of feminism by shining a light on the social construction of gender, sexuality and other intersections and the consequences and implications of that for society and people's position within society, and the composite character couple, which showed that lesbian parents had mixed experiences when accessing healthcare for their adopted children. Intersectionality ${ }^{42}$ is a lens through which power collision can be viewed alongside where it interlocks and intersects, therefore, how race, class, gender and other individual characteristics intersect with one another and overlap. It is a theory that asserts that people are often disadvantaged by multiple sources of oppression: their race, class, gender identity, sexual orientation, religion and other identity markers. It is common for a person to have multiple intersections, which make up their identity, ${ }^{43}$ which increases the likelihood of oppressive practice and microaggressions. Microaggressions emerge out of prejudice and discrimination and result in oppressive practices such as everyday hostile or derogatory behaviours and statements, which may be consciously or unconsciously delivered, ordinarily to members of targeted minority social groups such as LGBT people; people of differing skin colour; women; stigmatised religious groups. ${ }^{44}$ As a result of microaggressions, minority stress ${ }^{45}$ may also be felt by members of the minority group due to the relationship between minority and dominant values and resultant conflict within various environments, for example, in relation to this study, the healthcare environment. The theory of microaggressions was introduced in the 1970s and was related to racial microaggression, this has now spiralled to include other marginalised groups and has been found to be causally related to mental health issues due to the cumulative effects of subtle prejudice. ${ }^{46}{ }^{47}$ Data analysis revealed both positive and negative experiences and five overarching themes, with subthemes, which included strategies to overcome challenges which the parents faced.

\section{Navigating heteronormativity}

LGBT people are acknowledged as being invisible users of healthcare due to service provision being 'sexuality blind' and thereby treating LGBT people as if they are heterosexual. ${ }^{48}$ Sarah reported that due to the societal normative being heterosexist, she did not feel that as a family they were recognised as such and they were deflated as they had to explain their family construct as it was not always understood in English healthcare

'...in an ideal world, people would just automatically read two women with a child or children as both their mums but we're [as a society] nowhere near that point yet.' Sarah

\section{Strategies to navigate accessing heteronormative healthcare}

The strategies employed by the parents were used in order to protect the children and their familial identity and consisted of self-disclosure of sexuality and the use of power to navigate healthcare consultations.

Harriet used public self-disclosure of sexuality due to the importance of Courtney and Michael 'seeing' that they are a normal family.

'I out myself fairly quickly. So that's just a natural tendency that I do.' Harriet

Protecting healthcare professionals through selfdisclosure of sexuality was implemented by Harriet and Sarah, as when they had not done this previously, it led to assumptions being made about their family constellation.

'I think it's important to protect whoever you're interacting with... in this case the medical professional... so to protect them from feeling awkward and saying the wrong things. I suppose in that way it also protects them in front of [the children].' Sarah

Using power by having a professional link to healthcare, by wearing her work identification badge, was deemed by Sarah to be important in ensuring they received a positive experience in healthcare.

'...but because I work there now... I think it would be better... I'd wear my badge. Sarah

Harriet believed that she was not always treated differently, in a negative way, and apportioned this as potentially being due to her professional positioning, socioeconomic background and the area in which they lived.

'I think I'm treated differently because I'm articulate and because I'm white and educated... so if they identify you in some way as 'like them' then I think you are often treated better. I feel like I've been treated with respect because of those different markers. So I think if we were a same-gender couple from a different background we may well be treated very differently or if we're living in a different location. Harriet

The participants did not use the terms 'discrimination' or 'homophobia', however, from the narratives, it 
is evident that institutional homophobia is present and discrimination or 'being treated differently' remains apparent in English healthcare settings due to the examples of heteronormativity navigation and assumptions made about the participants' family constellation in health services in England.

\section{Navigating healthcare settings and professionals and having an 'adopted' status}

Harriet and Sarah commented that they often experienced incorrect terminology or negative attitudes discriminating against adoptive children/parents and, thus, felt that their identity was not accepted.

'We had to go to the one year health check for all looked after children and ...well considering they deal with adoption and adopted children they still don't get the terminology right... she said "“what about her real mum?" and it's like, we're her real mum! Sarah

Utilisation of the term 'real' needs to be considered due to the destabilising impact of this type of language, especially when heard by a child. Harriet also encountered a lack of adoption competence ${ }^{21}$ surrounding the legalities of adoption depicted by a healthcare professional, which highlights that some healthcare professionals wrongly consider that the biological parent has an inalienable lifelong right to be involved with the child.

'...We had to take Michael to the hospital and the consultant said "you know he has this condition and I think you need to ring his real mum because she has a right to know". I remember sat there thinking "no she lost that right the minute she laid a finger on him"... and it almost implies that she [birth mother] has some hold over him and that she can come at any point. How he interprets that...but they [the healthcare professionals] don't realise what damage they could be doing to his identity. Harriet

Utilising the correct terminology and understanding the legal status of adoption in order to demonstrate being adoption competent ${ }^{21}$ are imperative to ensure a secure family unit with no uncertainty. In addition, negative interactions can act as a trigger to children experiencing negative emotions about themselves.

\section{'Triggers' associated with adoption}

Adopted children may exhibit behaviour, which is not understood by people who are not known to them, for example, in health settings. Children who have experienced trauma, for example, due to fearful experiences or attending environments with other people from a fearful time in their lives, such as their early years, may suffer from 'triggers' of fearful situations. The 'trigger' is the capacity of the memory to bring elements of an experience from one moment in time to another ${ }^{49}$ and the brain may perceive that it is 'threatened' and, therefore, go into survival mode. In order for any experience, traumatic or not, to become part of a person's memory, it must be 'sensed', in order for this to occur it must be experienced by the individual person. The prime 'directive' of the human brain is to promote survival ${ }^{49}$ and each area of the human body and brain are used to respond to a 'threat' by going into 'survival mode'. This survival mode can look like 'challenging behaviour', enhanced and softened down emotional state and dysregulation of the child (or person) who has experienced the traumatic event previously and, therefore, is now enduring a 'trigger' ${ }^{30}{ }^{49}$ It is important to realise that the cognitive, emotional, social, behavioural and physiological effects of a trauma may impact an individual person for a great deal of time, sometimes for their lifetime. ${ }^{49}$

'She acts differently in doctors' offices... I don't know if it's because she had been with birth parents to the doctor's and so that was one of the differences in behaviou' Harriet

Harriet and Sarah furthered the discussion by drawing on the desire of some healthcare professionals to discuss birth history and the reason for adoption when it was unrelated to the appointment. The parents acknowledged that there were certain circumstances when healthcare professionals would need to discuss the child's biological background, although reported that these discussions did not need to occur in front of the children. These situations could have potentially been damaging to the child's welfare as they are in a health setting that could already trigger anxiety, and there were also discussions concerning the potentially traumatic background of the child.

'I think because they're adopted we often get asked things like, "Do you have parental responsibility, do you have a social worker or anyone else we should call?", which I understand because initially [at the first appointment] the adoption hadn't gone through but sometimes I just feel like that gets asked too often and I think Courtney is a really bright kid... you just see her ears pricking up a little bit at them asking. Sarah

This highlighted that healthcare professionals did not understand the adoption process and, thus, lacked adoption competence ${ }^{21}$ and, therefore, some of their consultation time was spent explaining the process and legalities before being able to address the children's health needs. Juxtaposed to these examples, Harriet commented on good practice, whereby a surgeon was aware of the effect that discussing 'triggering' information could have in front of the children.

'If he does want to ask something that's sensitive in terms of birth history or medical history, he gets them busy playing with something or takes one of us aside and asks us. He really considers their feelings. Harriet 
Unfortunately, from the findings of this study, this type of inclusion and sensitivity by healthcare staff are not common practice.

\section{'Hidden history' of adopted children}

One pertinent subtheme was the 'hidden history' of Courtney and Michael. This study has deemed 'hidden history' to mean 'the history of a child who is looked after by the local authority, in kinship care or adopted and due to their life experiences and movement between placements, elements of their life story are not fully known. This may be due to information transfer failure, death of family members or inability to verbalise the experiences by the child'.

Harriet commented that she sometimes felt judgement from healthcare professionals due to challenges Courtney and Michael had as a result of their hidden history.

'It's not really pleasant...to go to those appointments... every time we go to the dentist I get told to limit her sweets as she has got tooth decay and small cavities... and you feel like you're getting judged every time. Harriet

The presumption by healthcare professionals of parents being 'there' throughout the child's life is not an unnatural concept, however, healthcare professionals should be aware with adopted children that their adoptive parents may not have always been there and, therefore, provide additional support (and time) when needed. It is vital that 'hidden history' is added to the concept of adoption competence ${ }^{21}$ and that the English adoption process and the family constellation of being an adoptive family is acknowledged as 'normal' and intrusive questioning is limited.

\section{Intersectional identity of lesbian-parented adoptive families accessing healthcare}

The complexity of intersectional plays of adoption (and lack of understanding) in tandem with a heteronormative environment, led to challenges experienced by the participants with regards to terminology used by healthcare professionals within healthcare settings. Harriet and Sarah felt that they would probably delay seeking medical advice if a particular healthcare professional was not on duty, due to how other professionals have made them feel as a result of the intersections within their identities.

'If they read our file it helps. But we make the effort now if the children have got to go to the doctor's... we ask if Dr xxxx is in and I would go for that person even if it's the next day as they understand the adoption and being gay... I think potentially I would probably wait.' Sarah

Harriet employed a strategy of 'hiding' her intersections in order to have a better outcome when accessing healthcare for the children. She commented that when attending a health appointment on her own with Michael the questioning was different as she did not present as a lesbian couple with Sarah, therefore, the intersections of her identity, being a lesbian and an adoptive parent, were not apparent.

'The difference was that there was just me so suddenly all the issues disappeared because he was my son and we went through his birth history as if it were my history. And you almost can ignore it [the fact he's adopted] because it's not worth the hassle sometimes.' Harriet

While the focus of this study is the experiences of same-sex parents in healthcare, the intersection of race also requires discussion. Sarah's fear that, due to her ethnicity, she would not be taken seriously as a parent highlighted that she had to deal with compounding multiple oppressions. She, therefore, asked Harriet to take Courtney to the doctor's surgery as she felt that her concerns had been previously ignored and that the doctor would respond better to a white-skinned person given the discrimination and oppression black people are known to face within the healthcare system. ${ }^{50}$

'I said "look I'm not taking her to the doctor again because they have a habit of sectioning black people"... so [Harriet] took her...she got an inhaler straight away.' Sarah

'I sometimes feel that people will talk to you [Harriet] more...I do think it's a colour thing. White and Asian [health care professionals] will directly speak to [Harriet] more than they speak to me. I know it sounds really bad, but I'm used to it. Sarah

It is unacceptable that racism is a contributing factor to the level of engagement with healthcare professionals. Sarah's comment of being 'used to it' was also unacceptable as in line with law and policy ${ }^{32} 51$ and various healthcare professionals' codes of conduct, ${ }^{33-35}$ it is unlawful to discriminate against people on the basis of race.

This study has highlighted that intersectional play has a direct impact on the ability of lesbian parents to successfully navigate healthcare for their adopted children.

\section{Reflective imagery of lesbian parents and adoptive families}

In order to allow a sense of identity and inclusion, a family must be able to see their constellation reflected before them in society. Within the context of this study, this can be considered in wall posters and the administrative forms used by the NHS in England.

The forms used by healthcare professionals in England do not all use gender neutral terminology such as 'parent' or 'partner'. Therefore, universal heterosexuality is assumed and forms are exclusive to heterosexual parented families and, therefore, are not inclusive of diversity.

'We had to register him [Michael] at reception [primary care setting] and it [the form] had the usual... mums name...dads name. So we crossed out dad and just put mum.' Sarah 
Some healthcare professionals also made no attempt to amend a form to reflect the family dynamic, which led to the participants questioning the viability of their family construct in healthcare.

'They had a form at the hospital...where we just got put as adoptive parents, we don't get full status as parents...as if there's another parent somewhere hiding or there's another option. They've asked mum's name and dad's name. We've said there isn't a dad and given both of our names so they've just put one mums name down and haven't bothered filling in the rest of it! Just literally left it empty coz [sic] that was too tricky. Harriet

The insistence that Harriet and Sarah were named as adoptive parents (as opposed to parents) further supports an ideation that adoption is not 'normal'. Also, as neither of them identified as 'male' and, therefore, were not 'dad', one of them was completely ignored as part of the family.

In addition to administrative forms not being reflective of same-gender and adoptive families, it was also apparent that images of families in healthcare were also not reflective.

'I don't think I've seen anything... I find it pretty rare anywhere to see a lesbian couple with children depicted... and you do often see images that are one parent with a child or two parents of heterosexual families. Harriet

Lesbian adoptive mothers 'seek out' reflective imagery, be that through institutional forms recognising their family constellation or posters on the wall depicting diverse families. This study has highlighted that in order for lesbian parents and their adopted children to recognise themselves in healthcare bureaucracy and in poster representation, healthcare institutions must become more inclusive.

\section{Professional expectations}

Three of the study participants had an increased knowledge of professional codes of practice, alongside the standards expected of all healthcare professionals, which had an impact on service expectation. Harriet and Sarah highlighted that sometimes the healthcare professionals that they came into contact with lacked adoption competence $^{21}$ as they had gaps in their knowledge in relation to health conditions and the long-term effects of healthrelated challenges associated with adopted and looked after children.

'I don't expect them [health care professionals] to have a lot of adopted children [as their patients] but it should be something where you as a person [who is] not in the medical professional shouldn't have to try to educate them about what they're supposed to be doing or there should be something where they should be able to easily access what they're supposed to do.' Sarah

Within this theme, good practice was noted.

'[the surgeon] waited to do the surgery...until we were legally her parents because he wanted to give us that right to choose whether she had surgery or not. Rather than the social worker just signing a piece of paper and not really looking into whether it was good or bad...it [the consent form] was just a piece of paper to them. As a family we've been treated exactly the same as he treats everyone else and with consideration for the children and the terminology that he uses.' Harriet

An awareness of professional roles and attributes ascribed to healthcare roles was a discussion point, which was explored by one participant. Harriet focused on the healthcare professionals being in a position of trust and the disappointment when they did not recognise the privilege of the position that they were in.

'This person [healthcare professional] is in a position of trust and we have to listen to them...she was just so abrupt and lacked compassion and was so uncaring... whatever her feelings...it didn't come across that she was in a caring profession and there to make things ok for the children. Harriet

The theme of professional expectations has highlighted that healthcare professionals have a legal and ethical requirement through their professional standards ${ }^{33-35}$ to provide care, which is aligned to the Equality Act. ${ }^{32}$ This is echoed in the NHS Constitution. ${ }^{51}$ This study has highlighted that despite some excellent examples of inclusive practice, there still remains a rhetoric of heteronormativity and a lack of understanding of adoption in healthcare and the differences between being in foster care which is temporary, as opposed to being adopted, which is the permanent transfer of parental responsibility.

\section{DISCUSSION}

England legalised adoption for people who identify as LGBT in 2005, yet the participants of this study encountered microaggressions, institutional heteronormativity and behaviour, which was discriminatory. England has a diverse population demographic with multiple intersections, and all healthcare professionals should be able to communicate appropriately and inclusively with all members of the public that they have contact with. Questioning around parentage was more evident if both lesbian parents attended the health consultation, if only one parent attended, then it was rarely commented on unless the child had a complaint that was related to their early life experiences (such as Foetal Alcohol Spectrum Disorder).

In the majority of critical incidents shared by the participants, there was a heteronormative view portrayed by the 
healthcare professionals and questioning over the whereabouts of the 'father', which appears to be a prominent feature in children's healthcare ${ }^{19} 52$ and is coupled with heteronormative language. In addition there was a deep sense of a lack of adoption competence ${ }^{21}$ and consideration of the 'hidden history' of the children displayed by the healthcare professionals, which the participants believed should have been acknowledged and the healthcare professionals receive training on and also offer further support to the families if necessary. There was no reflective imagery of their family constellation in the healthcare, which could over time lead to an identity challenge and relied on the parent 'altering the form' to fit their constellation. Therefore, it can also be deduced that the behaviours of the healthcare professionals are endorsed by the institutional imagery, such as forms and posters being heteronormative.

The intersection of being an adopted child was also noted in this study and the microaggressive behaviour such as dehumanised terminology and invasive questioning regarding birth history by healthcare professionals were apparent. Being an adopted child and having lesbian parents increased the microaggressions and, therefore, discriminatory treatment that the family was subjected to, which is also a feature in international research. ${ }^{46}$ This brings the question as to whether the legal status of 'adopted and looked after children' should be a protected characteristic in the Equality $\mathrm{Act}^{32}$ to ensure that their identity is protected, especially when considering the impact of inclusion of other intersections of their identity such as, but not limited to, race, gender and sexual minority parents. The findings from this study show that while lesbian parents often have to tread a complex and heteronormative path within healthcare, ${ }^{1638}$ there are pockets of positive affirmation of lesbian parenthood, and these should be applauded and encouraged as 'gold standard' patient care.

\section{CONCLUSION}

This study has shown that the social construction of a family is dependent on people's own experiences and understanding of the term family, therefore, discrimination is apparent for adoptive families due to the family structure being a deviation away from the 'norm'. It is unacceptable and unlawful that heteronormative ideation persists within the NHS in the context of being a decade on from the Equality Act. ${ }^{32}$ The treatment of these children and their adoptive families is potentially harmful to their mental well-being, sense of self and sense of security in their adoptive family life; therefore, it can be argued that this is potentially a form of discrimination and oppression that must be recognised and addressed if necessary through reform and addition to the existing policies and law. The findings showed that the parents placed the children at the heart of their healthcare; this needs to be reciprocated by healthcare professionals, so that family-centred care and trauma-informed care are practised. In addition, the well-being of the adoptive parents should also be considered, which can be addressed by professionals being adoption competent ${ }^{21}$ and aware of hidden history. Practitioners should also receive training to ensure that they are aware of the adoption process in England; diversity of the population in which they practice; the importance of appropriate terminology and families seeing positive representation of adoption and same-gender parenting in healthcare settings.

\section{Twitter Lucille Kelsall-Knight @LKelsallIKnight}

Acknowledgements I would like to thank my doctoral supervisors (FM and DC) and the participants of this study, who gave so freely of their time.

Contributors I confirm that LKK is the sole author and investigator of this study and, therefore, undertook substantial contributions to the conception and design of the work; the acquisition, analysis or interpretation of data for the work. They also drafted the work and revised it critically for important intellectual content and gave final approval of the version to be published. In addition, they agree to be accountable for all aspects of the work in ensuring that questions related to the accuracy or integrity of any part of the work are appropriately investigated and resolved.

Funding The authors have not declared a specific grant for this research from any funding agency in the public, commercial or not-for-profit sectors.

\section{Competing interests None declared.}

Patient and public involvement Patients and/or the public were involved in the design, or conduct, or reporting, or dissemination plans of this research. Refer to the Methods section for further details.

Patient consent for publication Not applicable.

Ethics approval Ethical approval was obtained from the University of Wolverhampton in 2017. [Approval letter attached to file submission as no approval number/ID generated by ethics committee].

Provenance and peer review Not commissioned; externally peer reviewed.

Data availability statement Data are available upon reasonable request. All data is held securely in electronic format, but to maintain anonymity of the participants it is not available in its entirety as a supplementary file.

Open access This is an open access article distributed in accordance with the Creative Commons Attribution Non Commercial (CC BY-NC 4.0) license, which permits others to distribute, remix, adapt, build upon this work non-commercially, and license their derivative works on different terms, provided the original work is properly cited, appropriate credit is given, any changes made indicated, and the use is non-commercial. See: http://creativecommons.org/licenses/by-nc/4.0/.

ORCID iD

Lucille Kelsall-Knight http://orcid.org/0000-0002-8920-8179

\section{REFERENCES}

1 Mellish L, Jennings S, Tasker F. Gay, Lesbian and Heterosexual Adoptive Families: Family relationships, child adjustment and adopters' experiences. London: BAAF, 2013.

2 Golombok S. Modern families: parents and children in new family forms. Cambridge: Cambridge University Press, 2015.

3 Great Britain Parliament. Adoption and children act 2002. London: HMSO, 2002.

4 Rose P. Lesbian and gay parents: issues for paediatric nurses. Paediatr Nurs 1994;6:19-21.

5 Ahmann E. Working with families having parents who are gay or lesbian. Pediatr Nurs 1999;25:531-5.

6 Burkholder G, Burbank P. Caring for Lesbian, gay, bisexual, and transgender parents and their children. Int $J$ Childbirth Educ 2012;27:12-18.

7 Golombok S, Mellish L, Jennings S, et al. Adoptive gay father families: parent-child relationships and children's psychological adjustment. Child Dev 2014;85:456-68. 
8 Department for Education. Children looked after in England including adoptions. London: DfE, 2020.

9 Allen LB, Glicken AD, Beach RK, et al. Adolescent health care experience of gay, lesbian, and bisexual young adults. $J$ Adolesc Health 1998;23:212-20.

10 Perlesz A, McNair R. Lesbian Parenting: Insiders' Voices Australian and New Zealand. Journal of Family Therapy 2004;25:129-40.

11 Sharek DB, McCann E, Sheerin F, et al. Older LGBT people's experiences and concerns with healthcare professionals and services in Ireland. Int J Older People Nurs 2015;10:230-40.

12 Perrin EC, Kulkin H. Pediatric care for children whose parents are gay or lesbian. Pediatrics 1996;97:629-35.

13 Mikhailovich K, Martin S, Lawton S. Lesbian and gay parents: Their experiences of children's health care in Australia. International Journal of Sexuality and Gender Studies 2001;6:181-91.

14 McNair R, Brown R, Perlesz A, et al. Lesbian parents negotiating the health care system in Australia. Health Care Women Int 2008;29:91-114.

15 Rawsthorne ML. Just like other families? supporting Lesbianparented families. Australian Social Work 2009;62:45-60.

16 Chapman R, Wardrop J, Freeman P, et al. A descriptive study of the experiences of lesbian, gay and transgender parents accessing health services for their children. J Clin Nurs 2012;21:1128-35.

17 Malmquist A, Nelson KZ, Zetterqvist Nelson K. Efforts to maintain a 'just great' story: Lesbian parents' talk about encounters with professionals in fertility clinics and maternal and child healthcare services. Fem Psychol 2014;24:56-73.

18 Andersen A-E, Moberg C, Bengtsson Tops A, et al. Lesbian, gay and bisexual parents' experiences of nurses' attitudes in child health care-A qualitative study. J Clin Nurs 2017;26:5065-71.

19 Appelgren Engström H, Häggström-Nordin E, Borneskog C, et al. Mothers in same-sex relationships-Striving for equal parenthood: a grounded theory study. J Clin Nurs 2019;28:3700-9.

20 Kerppola J, Halme N, Perälä Marja-Leena, et al. Parental empowerment-Lesbian, gay, bisexual, trans or queer parents perceptions of maternity and child healthcare. Int J Nurs Pract 2019;25:1-8

21 Goldberg A, Frost R, Manley M. Lesbian, Gay, and Heterosexual Adoptive Parents' Experiences with Pediatricians: A Mixed-Methods Study. Adoption Quarterly 2019;29:669-81.

22 Chapman R, Watkins R, Zappia T, et al. Nursing and medical students' attitude, knowledge and beliefs regarding lesbian, gay, bisexual and transgender parents seeking health care for their children. J Clin Nurs 2012;21:938-45.

23 Shields L, Zappia T, Blackwood D, et al. Lesbian, gay, bisexual, and transgender parents seeking health care for their children: a systematic review of the literature. Worldviews Evid Based Nurs 2012;9:200-9.

24 Kelsall-Knight L. Experiences of LGBT parents when accessing healthcare for their children: a literature review. Nurs Child Young People 2021;33:17-24.

25 Neville S, Henrickson M. Perceptions of lesbian, gay and bisexual people of primary healthcare services. J Adv Nurs 2006;55:407-15.

26 Perrin EC, Cohen KM, Gold M, et al. Gay and lesbian issues in pediatric health care. Curr Probl Pediatr Adolesc Health Care 2004;34:355-98.

27 Dibley L. Experiences of lesbian parents in the UK: interactions with midwives. Evidence Based Midwifery 2009;7:94-114.

28 Edwards J, Roekel H. Gender, sexuality and embodiment: access to and experience of healthcare by same-sex attracted women in Australia. Current Sociology 2009;57:193-210.

29 Radel LF, Blumberg SJ, Blumberg SJ. The health and well-being of adopted children. Pediatrics 2007;119 Suppl 1:S54-60.
30 Verrier N. The Primal wound: understanding the adopted child. London: BAAF, 2009.

31 Salter A. The Adopter's Handbook. London: BAAF, 2013.

32 Great Britain Parliament. Equality act 2010. London: HMSO, 2010.

33 General Medical Council. Good medical practice. London: GMC, 2014

34 Health and Care Professions Council. Standards of proficiency: Paramedics. London: HCPC, 2014

35 Nursing and Midwifery Council. The code. London: NMC, 2015.

36 Stonewall. Being the gay one: experiences of Lesbian, gay and bisexual people working in the health and social care sector. London: Stonewall, 2008.

37 Commons Select Committee. Health and social care and LGBT communities, 2019. Available: https://www.parliament.uk/business/ committees/committees-a-z/commons-select/women-andequalities-committee/news-parliament-2017/lgbt-health-social-carereport-published-19-20/ [Accessed May 2021]

38 Kelsall-Knight L, Sudron C. Non-Biological lesbian mothers' experiences of accessing healthcare for their children. Nurs Child Young People 2020;32:38-42.

39 Clandinin DJ, Connelly FM. Narrative inquiry: experience and story in qualitative research. San Francisco: John Wiley, 2000.

40 Webster L, Mertova P. Using narrative inquiry as a research method: an introduction to using critical event narrative analysis in research on learning and teaching. Oxon: Routledge, 2007.

41 Rich A, Parker DL. Reflection and critical incident analysis: ethical and moral implications of their use within nursing and midwifery education. J Adv Nurs 1995;22:1050-7.

42 Crenshaw K. Demarginalizing the intersection of race and sex: a black feminist critique of Antidiscrimination doctrine, feminist theory and Antiracist policies. University of Chicago Legal Forum 1989;140:139-67.

43 McCann H, Monaghan W. Queer theory now. London: Red Globe Press, 2020.

44 Sue D. Microagressions and marginality: manifestation, dynamics and impact. New York: Wiley, 2010.

45 Meyer IH. Prejudice, social stress, and mental health in lesbian, gay, and bisexual populations: conceptual issues and research evidence. Psychol Bull 2003;129:674-97.

46 Farr RH, Crain EE, Oakley MK, et al. Microaggressions, feelings of difference, and resilience among adopted children with sexual minority parents. J Youth Adolesc 2016;45:85-104.

47 Nadal KL, Whitman CN, Davis LS, et al. Microaggressions toward Lesbian, gay, bisexual, transgender, Queer, and Genderqueer people: a review of the literature. J Sex Res 2016;53:488-508.

48 Fish J. All things equal? Social work and LGB global health inequalities. In: Bywaters P, Napier L, McLeod E, eds. Social work and global health inequalities. Bristol: The Policy Press, 2009: 144-9.

49 Goldstein DS, Perry BD. (1999) Maltreated children: experience, brain development and the next generation. New York and London: W.W. Norton, 1995.

50 Salway S, Mir G, Turner D, et al. Obstacles to "race equality" in the English National Health Service: Insights from the healthcare commissioning arena. Soc Sci Med 2016;152:102-10.

51 Department of Health. The NHS constitution for England. London: $\mathrm{DoH}, 2015$.

52 Connell R, Pearse R. Gender norms and stereotypes. A survey of concepts, research, and issues about change. un women, 2014. Available: https://www.unwomen.org/ /media/headquarters/ attachments/sections/csw/59/csw59-egm-bp2-connell-pearse-en. pdf [Accessed May 2021]. 